\title{
The Stability of Peroxide lons and Superoxide Ions in Fused LiCl-KCl Eutectic
}

\author{
Yasushi KANZAKI*, Kazuo KOGAWA*, Seiji YANO*, \\ Osamu Matsumoto* and Masao TAKAHASHI**
}

The oxygen electrode in fused salts can generally be assumed as

$$
2 \mathrm{O}^{2-}-4 e=\mathrm{O}_{2}(\mathrm{~g})
$$

Various kinds of reaction mechanisms have been proposed for this reaction. In lithium chloride-potassium chloride eutectic, for example, the following reaction scheme has been posturated by Wrench $e_{t}^{t} a l$.

$$
2 \mathrm{O}^{2--}-2 e \longrightarrow \mathrm{O}_{2}{ }^{2-}
$$

$\mathrm{O}_{2}{ }^{2-}-2 e \longrightarrow \mathrm{O}_{2}$ (potential determining step) from the analysis of the polarization curve ${ }^{\text {) }}$ and the Nernst plot $^{2}$. They concluded that the reversible oxygen electrode was impossible to be constructed in the melt. Zambonin et al..$^{3) \sim 5}$ and Jordan ${ }^{6}$ ) have suggested that the oxygen evolution reaction consists of a series of the following elementary steps in fused nitrate salts.

$$
\begin{aligned}
& \mathrm{O}_{2}{ }^{2-}-e \longrightarrow \mathrm{O}_{2}{ }^{-} \\
& \mathrm{O}_{2}{ }^{-}-e \longrightarrow \mathrm{O}_{2}
\end{aligned}
$$

The oxide ion, $\mathrm{O}^{2-}$, was considered to be unstable in this melt. The peroxide ion, $\mathrm{O}_{2}{ }^{2-}$, and the superoxide ion, $\mathrm{O}_{2}^{-}$, are thermodynamically stable species in accordance with these investigations. On the other hand, two of the authors, Y.K. and M.T., have proved that the reversible oxygen electrode, eqn. 1, was probable in fused lithium chloride-potassium chloride eutectic $^{7)^{8}}$. The presence of peroxide and superoxide ions was hardly detected in their experiment.

In this note the stability of above anions concerned in oxygen was examined in fused

\footnotetext{
* Department of Chemistry, College of Science and Engineering, Aoyama Gakuin University, (6-16-1 Chitosedai, Setagaya-ku, TOKYO)

** Institute of Materials Science and Engineering, Faculty of Engineering, Yokohama National University, (Ohoka-machi, Minami-ku, Yokohama)
}

lithium chloride-potassium chloride eutectic by means of voltammetry and potentiometry.

Experimental procedures were almost the same as those in the previous paper" ${ }^{2}$. The electrolytic cell was made of platinum to reduce the effect of glass material which consumes oxide ions. The platinum sphere electrode was used as the working electrode. The reference electrode was the $\mathrm{Ag} / \mathrm{Ag}^{+}(0.05)$ system. Polarization curves were obtained by the potential sweep method $^{9,10)}$. Lithium oxide, sodium and barium peroxides and potassium superoxide were used as the anion donors, $\mathrm{O}^{2-}, \mathrm{O}_{2}{ }^{2-}$ and $\mathrm{O}_{2}^{-}$, respectively.

Polarization curves for the oxidation of oxide ions have already been presented in the preceding paper ${ }^{7)}$. A typical example is shown in Fig. 1. The oxygen evolution from oxide ions is observed at about $+0.2 \mathrm{~V}$. The currentpotential characteristic of this reaction was independent of the electrode material, platinum,

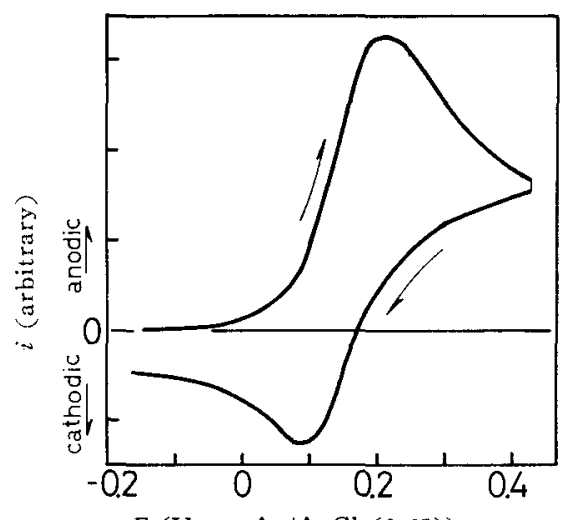

$E(\mathrm{~V}$ vs. $\mathrm{Ag} / \mathrm{AgCl}(0.05))$

Fig. 1 Anodic cyclic voltammogram of oxide ions in $\mathrm{LiCl}-\mathrm{KCl}$ eutectic at scan rate $0.16 \mathrm{VS}_{\mathrm{s}}{ }^{-1}$ Temp. : $400^{\circ} \mathrm{C}$, Electrode: $\mathrm{Pt}$ 
paradium and rhodium, with the exception of gold $^{2}$. The reaction scheme has been proposed as $\mathrm{O}^{2-}-2 e=\mathrm{O}, \mathrm{O}+\mathrm{O}=\mathrm{O}_{2}$. The electrode potential of this system satisfied the Nernst relation.

The equilibrium of oxygen with the oxide ion, the peroxide ion and the superoxide ion can be shown as :

$$
\begin{aligned}
& \mathrm{O}_{2}{ }^{2-}=\mathrm{O}^{2-}+1 / 2 \mathrm{O}_{2} \\
& \mathrm{O}_{2}{ }^{-}=1 / 2 \mathrm{O}_{2}{ }^{2-}+1 / 2 \mathrm{O}_{2}
\end{aligned}
$$

The dissociation constants of these systems have not yet been determined as far as we know.

The anodic polarization curve of peroxide ions was quite similar to that in case of oxide ions. The addition of superoxide gave a similar result. Any sign for the reduction of peroxide and superoxide ions as well as the oxidation of them was scarecely observed in the polarization curve. Absence of these ions was also examined from the coloring of the clotted melt and the reactivity of it with water. Fig. 2 shows the relation of the maximum current of the oxygen evolution (See Fig. 1.) against the amount of added oxide, peroxide and superoxide. As for oxide ions detailed discussion will be abbreviated since the reaction has precisely been examined in the preceding paper ${ }^{7)}$. The addition of peroxide gave a similar result as that of the oxide addition. The fact shows that the greater part of the peroxide ions dissociated into oxide ions and oxygen, for one peroxide ion should give one oxide ion if the equilibrium of eqn. 2 inclines to the right. Curve 3 in Fig. 2 shows the result of the superoxide ion. According to eqns. 2 and 3 , it is expected that the current hight of superoxide ions is a half of

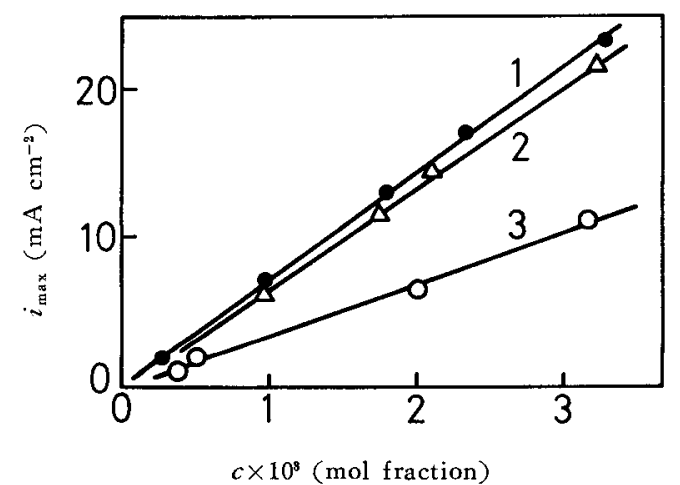

Fig. $2 i_{\max } v s$, added amount of oxide, peroxide and superoxide at scan rate $0.16 \mathrm{Vs}^{-1}$ Temp.: $400^{\circ} \mathrm{C}$. $: \mathrm{Li}_{2} \mathrm{O}, \triangle: \mathrm{BaO}_{2}, \mathrm{O}: \mathrm{KO}_{2}$

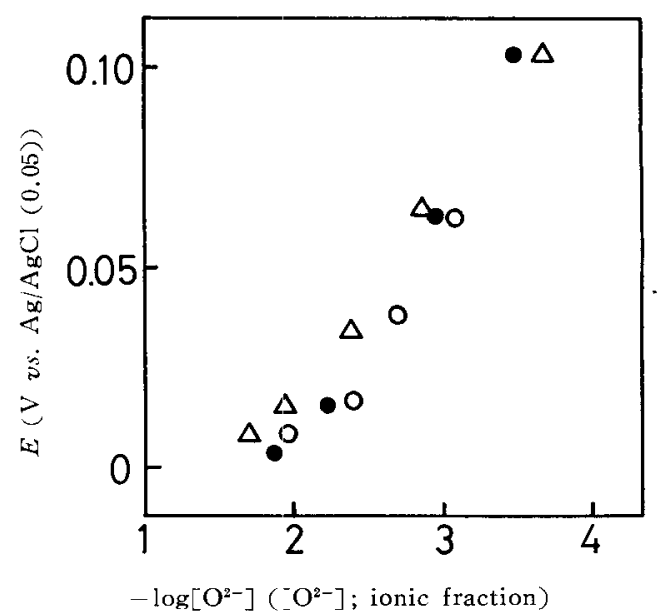

Fig. 3 Nernst plots of $\mathrm{Li}_{2} \mathrm{O} / \mathrm{O}_{2}, \mathrm{BaO}_{2} / \mathrm{O}_{2}$ and $\mathrm{KO}_{2} / \mathrm{O}_{2}$ systems at $400^{\circ} \mathrm{C}$

$\mathrm{P}_{\mathrm{O}_{2}}=1$ atm, Electrode: $\mathrm{Pt}$, Abscissa is shown by concn. of $\mathrm{O}^{2-}$ which are estimated from maximum current. (See Figs. 1 and 2.) $: \mathrm{Li}_{2} \mathrm{O}, \triangle: \mathrm{BaO}_{2}$, $\mathrm{O}: \mathrm{KO}_{2}$

that for the oxide ions if equilibria of eqns. 2 and 3 incline considerably to the right hands. Although the current obtained by the superoxide addition was a little bit larger than that of the expected value, it was concluded that two superoxide ions gave one oxide ion. Such a presumption may be allowed if the atmospheric contamination, moisture, is taken into consideration. The degree of contamination was roughly estimated from the hydroxide ion wave $^{7), 11)}$.

Figure 3 shows the Nernst plots of $\mathrm{Li}_{2} \mathrm{O}_{1} \mathrm{O}_{2}$, $\mathrm{BaO}_{2} / \mathrm{O}_{2}$ and $\mathrm{KO}_{2} / \mathrm{O}_{2}$ systems. They gave a similar result. This finding shows the absence of peroxide and superoxide ions.

In accordance with the present investigation it was found that the peroxide ions and superoxide ions are thermodynamically unstable in the chloride melts at about $400^{\circ} \mathrm{C}$ and the greater part of them decomposes into oxide ions and oxygen gas. The presence of a small amount of peroxide ions and/or superoxide ions was expected to be left undecomposed since some change of the electrode surface before and after the polarization measurement was observed. Kinetic stability of peroxide and superoxide ions, i.e. the role as an intermediate of the electrode reaction, is left behind as a further problem. 
Acknowledgement :

This work is a part of a research program of the US-Japan Co-operative Science Program sponsored by the Japan Society for the Prornotive of Science.

$<\mathrm{E} 413>$ (Received March 6,1975)

\section{References :}

1) P. Delahay (Ed.), Advances in Electrochemistry and Electrochemical Engineering Vol. 4, p. 144 (1966), Interscience, New York.

2) N.S. Wrench, D. Inman, J. Electroanal. Chem. 17, 319 (1968).

3) P.G. Zambonin, J. Jordan, J. Am. Chem. Soc. 89,
6365 (1967).

4) P.G. Zambonin, J. Jordan, ibid. 91, 2225 (1969).

5) P.G. Zambonin, J. Electroanal. Chem. 24, App. 25 (1970).

6) J. Jordan, ibid. 29, 127 (1971).

7) Y. Kanzaki, M. Takahashi, ibid. 58, 339 (1975).

8) Y. Kanzaki, M. Takahashi, ibid. 58, 349 (1975).

9) J.E.B. Randles, Trans. Faraday Soc. 44, 327 (1948).

10) A. Sevcik, Collection Czechoslov. Chem. Communs. 13, 349 (1948).

11) K. Kogawa, B.S. Thesis, Aoyama Gakuin University, 1975 . 